\title{
Psicologia Escolar: análise sobre dificuldades e superações no Brasil e Portugal
}

\author{
Ana Paula Petroni \\ Pontifícia Universidade Católica de Campinas - Campinas - SP - Brasil \\ Vera Lucia Trevisan de Souza \\ Pontifícia Universidade Católica de Campinas - Campinas - SP - Brasil
}

\section{Resumo}

Apresentamos neste artigo algumas considerações acerca da constituição e do fortalecimento da Psicologia Escolar como área de conhecimento e de prática. O objetivo é problematizar o modo como a atuação do psicólogo escolar tem sido representada e nos aproximarmos de uma visão mais crítica com relação a sua prática. Para isso, buscamos apresentar um cenário de como essa área vem sendo construída e constituída no Brasil e em Portugal. Acreditamos que as reflexões aqui desenvolvidas oferecem lastro para a atuação do psicólogo na escola, possibilitando a construção de uma ação crítica que incorpora as condicionantes históricas, políticas e econômicas que constituem esta instituição e se volta ao seu enfrentamento, pela aposta nos sujeitos e suas objetivações, como protagonistas de suas histórias, seu desenvolvimento e sua aprendizagem.

Palavras-chave: Psicologia Escolar e Educacional; escolas; políticas.

\section{School Psychology: analysis of difficulties and overruns in Brazil and Portugal}

\begin{abstract}
This paper presents some considerations for the establishment and strengthening of School Psychology as a field of knowledge and practice. The intention is to discuss how the work of the school psychologist has been represented, bringing us a more critical view in their practice. For this, we present a brief scenario of how this area has been built and incorporated in Brazil and Portugal. We think that the reflections presented here provide ballast for the psychologist in school, enabling the construction of a critical action that incorporates the historical conditions, political and economic constituting the institution, and turns to face it, bet on the subjects and their objectivities as protagonists of their history, their development and learning.
\end{abstract}

Keywords: School and Educational Psychology; schools; politics.

\section{Psicología Escolar: análisis sobre dificultades y superaciones en Brasil y Portugal}

\section{Resumen}

Presentamos en este artículo algunas consideraciones acerca de la constitución y del fortalecimiento de la Psicología Escolar como área de conocimiento y de práctica. El objetivo es problematizar el modo como la actuación del psicólogo escolar ha sido representada y acercarnos de una visión más crítica en relación a su práctica. Para eso, buscamos presentar un escenario de como esa área viene siendo construida y constituida en Brasil y en Portugal. Creemos que las reflexiones aquí desarrolladas ofrezcan lastro para la actuación del psicólogo en la escuela, posibilitando la construcción de una acción crítica que incorpora las condicionantes históricas, políticas y económicas que constituyen esta institución y se vuelve a su enfrentamiento, por la aposta en los sujetos y sus objetivaciones, como protagonistas de sus historias, su desarrollo y su aprendizaje.

Palabras clave: Psicología Escolar y Educacional; escuelas; políticas. 


\section{Introdução ${ }^{1}$}

\begin{abstract}
Marcos disse que a nossa presença na escola é algo que incomoda a todos, inclusive a secretária [da escola], que comentou sobre estarmos na escola e questionou-o sobre o que seria feito na reunião. Ele respondeu a ela que nós fazíamos uma terapia em grupo; ela se espantou que fizéssemos isso de graça e disse que gostaria de ter esse serviço também (Trecho da síntese do $15^{\circ}$ encontro - 13 de setembro de 2010) ${ }^{2}$.
\end{abstract}

Apesar de a proposta deste artigo não ser um relato de pesquisa, optamos por iniciar este texto com um excerto retirado de uma síntese construída a partir de um dos encontros realizados ao longo de uma pesquisa-intervenção com a equipe gestora de uma escola municipal de Ensino Fundamental e Educação de Jovens e Adultos (Petroni, 2013), pois ele indica como a atuação do psicólogo escolar ainda é representada nos dias de hoje.

Atuamos nessa escola entre os anos de 2007 a 2013 e, mesmo afirmando sempre que o trabalho que fazíamos não era clínico, com enfoque terapêutico, que essa não era nossa função naquele espaço, mas sim a de estabelecer uma parceria para pensarmos ações voltadas à escola como um todo, era recorrente a fala de que estávamos lá para fazer terapia. Essa representação do trabalho do psicólogo escolar nos levou a alguns questionamentos: qual seria o papel desempenhado pelo psicólogo na escola? Como construir um espaço para desenvolvermos um trabalho efetivo? Como estabelecer parcerias legitimadas? Essas questões, suscitadas também pelo excerto acima, são tomadas como norteadoras das reflexões que apresentamos neste artigo.

Acreditamos que a representação da profissão do psicólogo como clínico se encontra cristalizada nos sujeitos, e a própria Psicologia, de certo modo, tem contribuído para sua manutenção. Pensamos que a raiz dessa problemática reside na necessidade de conhecermos mais profundamente o modo como os psicólogos têm desenvolvido seu trabalho na escola e a própria compreensão da Psicologia Escolar como campo de ação profissional.

Um dos primeiro passos nesse caminho é acessarmos as produções científicas, conforme apontado por Marinho-Araujo (2010), que nos permitem não só conhecer as problemáticas da área, mas também nos ajudam a direcionar e consolidar nossa atuação, na medida em que oferecem subsídios teóricos e práticos que fundamentam essa construção. Os estudos existentes nos aproximam das

1 Este artigo conta com informações colhidas e construídas durante a realização de estágio de doutoramento Sanduíche em Portugal (processo n 0239/12-7 - CAPES), sob a orientação da Professora Doutora Anabela Maria Sousa Pereira, da Universidade de Aveiro. Agradecemos, também, ao Professor Leandro Almeida, da Universidade do Minho, pelas informações fornecidas.

2 O nome utilizado é fictício e o trecho apresentado compõe os dados da pesquisa de doutorado disponível em: http://www. bibliotecadigital.puc-campinas.edu.br/tde_arquivos/6/TDE-2013-0314T071717Z-1787/Publico/ANA\%20PAULA\%20PETRONI\%20.pdf realidades vivenciadas pelos atores escolares e indicam as demandas à Psicologia que emergem desse contexto. No entanto, este é um movimento necessário desde a formação inicial dos futuros psicólogos, sendo que na constituição profissional, ensino e pesquisa se articulam.

E é justamente a diversidade de demandas postas pela escola, relativas aos sujeitos em suas singularidades, ao coletivo e sua construção, e às relações entre pessoas de diferentes idades, classe social, interesses, valores, desejos, enfim, que confere à ação do psicólogo escolar grande desafio, sobretudo na eleição e planejamento de ações que se voltem a essa diversidade que constitui a Educação.

Nesse sentido, afirmam Guzzo, Mezzalira, Moreira, Tizzei e Silva Neto (2010):

O amadurecimento de uma profissão está relacionado ao quanto uma determinada área de conhecimento se consolida e à perspectiva da relação que o conhecimento teórico estabelece com a prática e com as demandas da realidade. A relação da Psicologia com a Educação não é diferente. Apesar de estreita e antiga, é no bojo das circunstâncias concretas que ela se consolida em teoria e prática (p. 131).

Essa afirmação sintetiza o que vimos defendendo e justifica a problematização das demandas postas à Psicologia Escolar à luz do que vem sendo discutido e produzido na área. É das condições materiais, concretas, que emergem os problemas de pesquisa, os interesses de investigação, as relações estabelecidas entre os sujeitos, as condições para exercer nosso trabalho. Conhecer essas condições e o modo como elas foram sendo produzidas ao longo da história, identificando suas objetivações nas produções em Psicologia Escolar é o que nos propomos neste artigo.

Ressaltamos que para o cumprimento desses propósitos, faremos um recorte de informações a respeito da Psicologia Escolar no Brasil e em Portugal, construídas durante a realização de um estágio de doutoramento; porém, não desconsideramos a existência de esforços em todo o mundo para a consolidação desta área de conhecimento.

\section{A Psicologia e a escola: breves considerações sobre a área no Brasil e em Portugal}

Trabalhos como o de Antunes (2003), Guzzo e cols. (2010), Marinho-Araujo (2010), Souza, M. (2010), revelam o percurso que foi sendo traçado ao longo da história na construção da relação entre a Psicologia e a Educação, indicando que a entrada do psicólogo na escola, em meados do século $X X$, se deu principalmente pelas portas da avaliação psicológica, prática em evidência na época, para atender a queixa dos educadores, em especial sobre alunos tidos como difíceis, com problemas de aprendizagem, que necessitavam de diagnóstico.

Porém, já nas décadas de 1970 e 1980, tem início uma preocupação em questionar essa atuação do psicólogo, buscando-se refletir sobre sua inserção e atuação na escola. 
Desde então, temos acompanhado os esforços endereçados ao fortalecimento e à legitimação dessa área de atuação e de conhecimento.

A criação da Associação Brasileira de Psicologia Escolar e Educacional (ABRAPEE) e, também, do Grupo de Trabalho em Psicologia Escolar/Educacional da Associação Nacional de Pesquisa e Pós-Graduação em Psicologia (ANPEPP), são exemplos de movimentos que resultaram dos esforços empreendidos pelos pesquisadores e profissionais para a consolidação desse campo de atuação e pesquisa. As discussões que ainda hoje têm sido promovidas demonstram destacam o que há por avançar para que a Psicologia Escolar se firme com área que tem muito a contribuir com fundamentos para teoria e prática.

Essas inquietações em relação à Psicologia Escolar nos conduziram a investigar sua condição como área de pesquisa e prática profissional em Portugal, pois acreditamos que dessa forma poderíamos encontrar contribuições para a superação dos desafios da área em nosso país.

Trabalhos como os de Almeida (1993, 2003), Jesus (2004) e, mais recentemente, o texto de Mendes, Abreu-Lima e Almeida (2013), mostram que a via que possibilitou a inserção dos psicólogos nas escolas naquele país também foi a da avaliação. De acordo com Almeida (1993), os psicólogos adentraram as escolas portuguesas a fim de atender, respectivamente, a quatro principais demandas: realização de avaliações e acompanhamento de crianças, em particular daquelas que apresentavam necessidades especiais; formação psicológica dos educadores; orientação escolar e profissional; e promoção do sucesso educativo de crianças do ciclo básico.

Como apontado por Silva Neto (2015), a inserção do psicólogo no contexto escolar em Portugal se legitimou a partir da promulgação de duas leis: "1986 - Previsão na Lei de Bases do Sistema Educativo (Lei n 46/86, 1986) de ações de psicológica em contexto escolar; e 1991 - Regulamentação própria dos Serviços de Psicologia e Orientação (SPOs) - Decreto-lei n 190/91 (1991) responsáveis por direcionar as práticas dos psicólogos nas escolas" (p. 1373), como veremos adiante.

Mesmo com a existência dessas políticas, ainda nos deparamos com um cenário que se caracterizava pela busca da afirmação da profissão no país, liderada pela Ordem dos Psicólogos Portugueses. Esse parecia ser, para nós, um momento favorável para se investir na reflexão acerca da formação dos psicólogos e sobre as pesquisas que vem sendo desenvolvidas, o que contribui para o avanço da prática desses profissionais no país.

Aqui no Brasil também temos encontrado esforços nesse sentido, seja por parte do Conselho Federal de Psicologia e dos Conselhos Regionais, seja por parte das associações citadas anteriormente. Contudo, Guzzo e Mezzalira (2011) afirmam que:

...apesar do esforço e dos gastos empreendidos em garantir reuniões municipais, regionais e nacionais, mobilizando uma massa considerável de profissionais psicólogos para as discussões, seus resultados são muitopequenos, e o que se observa é que o perfil profissional não se altera, substancialmente, ao longo de décadas. A Psicologia segue sendo uma profissão e uma ciência em que predominam conhecimentos e prática voltados para a classe dominante, ainda não efetivamente envolvida com as causas sociais e com as mudanças da realidade brasileira (pp. 11-12).

Essa colocação suscita algumas questões: o que seria necessário para promover o avanço da Psicologia Escolar no Brasil como área de atuação profissional e produção de conhecimento? Quais aspectos precisariam ser destacados? O que se encontra na base dessa não mudança? A quem se destinam, de fato, os serviços de Psicologia?

Souza, V. (2008) pontua que, no processo de construção da identidade do psicólogo, a representação de um profissional que se volta para a clínica é a que mais se evidencia; e esse também é um aspecto ressaltado por Guzzo e Mezzalira (2011), ao afirmarem que o psicólogo acabou sendo colocado para fora da escola por ser considerado um profissional da saúde, que deveria se ocupar das doenças e desenvolver seu trabalho em espaços clínicos.

Muito próximo a isso, localizamos em Portugal o trabalho de Coimbra (1991), que apresenta um modelo de atuação do psicólogo que denomina de "colaborativo", em contraposição ao denominado de "especialista". Este último modelo é entendido como aquele em que não há parceria entre o psicólogo e os outros profissionais/atores escolares; o psicólogo é visto como o profissional detentor de técnicas específicas e particulares que possibilitam a divisão entre o que caberia ao psicólogo e ao professor.

Poderíamos dizer que o modelo colaborativo proposto por Coimbra (1991) se aproxima do que temos defendido no Brasil atualmente sob a denominação de modelo crítico de atuação, o qual se caracteriza por uma atuação em colaboração com os atores escolares. Ele possibilita a realização de intervenções em que a parceria entre todos os profissionais da escola é valorizada. O psicólogo passa a ser integrante da equipe e se faz necessário que ele conheça toda a complexidade que constitui o meio no qual ele atuará. Esse modelo é o que temos defendido em nossas pesquisas e intervenções.

Acreditamos que não seja possível planejar ou desenvolver uma intervenção que não se paute pela colaboração, pela parceria, pelo compartilhamento da visão de que a qualidade das relações entre os sujeitos é fundamental para seu desenvolvimento, para a sua aprendizagem. Porém, precisamos considerar as contradições presentes na base dessas discussões: ao mesmo tempo em que há produções que defendem uma atuação mais crítica, ainda encontramos profissionais com práticas voltadas à individualização, minimizando o potencial do sujeito e o peso das condições materiais em que vive.

Souza (2010), ao fazer um levantamento das produções da área da Psicologia Escolar, pontua essa questão:

...apesar dos autores proporem uma atuação baseada em uma perspectiva crítica, há uma diversidade de modos de compreender a instituição escolar e as relações que nela se 
dão, pois se verificou que existem psicólogos que defendem que a tônica do fracasso escolar é de responsabilidade da criança, ou seja, buscam explicações e justificativas no mundo interno da criança, nos problemas familiares, na carência cultural e em outros fatores, acabando por excluir a escola deste processo (p. 73).

O que se destaca é o fato de a escola ser desconsiderada nesse processo. Como esperar que seja construída uma identidade profissional de psicólogo escolar que se sustenta em uma visão crítica da realidade se seu lócus de atuação é desconsiderado? Ao assumir uma perspectiva crítica, assume-se a responsabilidade de se levar em conta toda a complexidade do espaço em que se realiza a atuação profissional. Pensamos que, talvez, resida aí o compromisso ético e político do psicólogo com a educação em geral, com a escola e com todos os sujeitos que nela se encontram, sejam alunos, professores ou gestores.

Tem-se defendido que para se fortalecer esse modo de atuação denominado crítico, é preciso investir na produção de pesquisas e práticas que, uma vez socializadas, promovam reflexões sobre o lugar do psicólogo na escola. No entanto, é preciso cuidar para que essas produções tragam contribuições efetivas para a área, o que se constitui como nosso principal desafio como pesquisadores.

Essa problemática também se apresentou em um dos trabalhos acessados em Portugal. Machado, Lourenço, Pinheiro e Silva (2004), relatando pesquisa em que analisaram três revistas portuguesas de Psicologia, apontam que a área escolar/educacional é, juntamente com a área clínica, a que mais tem publicações no referido país, sendo que as temáticas discutidas discorriam sobre problemas cognitivos, emocionais e comportamentais, que se manifestam durante o processo de aprendizagem dos alunos.

Concordamos com os autores (Machado \& cols., 2004) que é necessário investir em pesquisas que focalizem e busquem explicar questões mais complexas, de natureza social e relacional. Precisamos avançar nas pesquisas no sentido de produzir mais respostas e explicações sobre os problemas investigados. Há, também, outro investimento que precisa ser feito quando falamos em avanços da Psicologia Escolar. É preciso repensar a formação do profissional de Psicologia, seja ela inicial ou continuada. Os autores que se dedicam ao estudo dessa dimensão têm demonstrado a importância da formação na constituição de uma identidade profissional que permita ao psicólogo atuações voltadas a contextos mais amplos da sociedade.

Também encontramos em Portugal vozes dissonantes em relação ao que deve ser a Psicologia na escola. Carvalho (2008) defende que na intervenção realizada pelos psicólogos é preciso levar em consideração todos os aspectos que circundam as escolas e seus sujeitos, sendo que as mudanças atuais da sociedade influenciam diretamente esse contexto. $O$ autor também afirma que ainda não há uma definição e concepção claras do que cabe ao psicólogo realizar nas escolas. Ao propor um modelo de atuação que tem como base a abordagem ecológica, fundamenta uma intervenção em torno de quatro eixos principais: a integração do psicólogo com a comunidade educativa, com vistas ao desenvolvimento de um trabalho mais eficaz; a cooperação entre os diversos atores escolares, evitando dessa forma, um trabalho em que o psicólogo aja isoladamente; a participação nas diversas atividades desenvolvidas na escola, e não somente naquelas destinadas aos serviços de psicologia; e a prevenção, realizada por meio de "estratégias que pretendem diminuir a possibilidade de surgimento de problemáticas futuras, evitando-se, com isso, estratégias de remediação" (p. 124).

Observa-se, assim, a preocupação com a construção de um modelo de atuação do psicólogo na escola que se contraponha ao que parece hegemônico em Portugal. Contudo, ainda que se considere a importância deste movimento, ele parece distante de alcançar um modelo crítico de atuação, e, neste sentido, podemos afirmar que em muito já avançamos no Brasil.

\section{As políticas para a inserção do psicólogo na escola no Brasil e em Portugal}

De acordo com o levantamento realizado por Souza (2010), em 133 municípios do estado de São Paulo, 61 deles contavam com o psicólogo compondo o quadro de funcionários das respectivas Secretarias de Educação municipais, contabilizando 220 profissionais atuando no campo da Psicologia Escolar. O modo como esses serviços de Psicologia se organizam nesses municípios compreende a formação de equipes de psicólogos que atendem às demandas da rede ou por um único psicólogo que responde por todas as demandas encaminhadas pelas escolas, sendo as funções desenvolvidas categorizadas como: psicólogo, psicólogo escolar, psicólogo educacional e psicólogo da educação.

O que esses dados revelam é que, apesar de haver psicólogos atuando nas redes de ensino, ainda há prejuízos no que diz respeito às suas ações, pois o número de profissionais inseridos nesse campo não atende às demandas que emergem desses contextos. Apesar dos avanços da Psicologia Escolar no que se refere à produção científica ou apropriação de práticas mais efetivas, ainda não há, no Brasil, uma política que garanta a inserção do psicólogo nas escolas.

Temos como referência para a atuação do psicólogo na escola as atribuições constantes no Catálogo Brasileiro de Ocupações, do Ministério do Trabalho (2008), assim como na Resolução 13/2007 do Conselho Federal de Psicologia (2007). De acordo com esses documentos, caberia ao psicólogo que atua em contextos educativos, realizar pesquisa, diagnósticos e intervenção junto aos atores escolares (alunos, professores e gestores), seja de modo individual ou coletivo, no que diz respeito aos processos de ensino e aprendizagem (dificuldades, promoção, planejamentos, técnicas), orientação profissional e vocacional, auxílio na elaboração de projetos pedagógicos, questões relacionadas à inclusão de alunos com necessidades educativas especiais, analisa 
as relações estabelecidas entre os atores escolares; em sua prática fica evidenciada a importância da parceria com os outros profissionais a escola, integrando os conhecimentos psicológicos aos outros utilizados para a compreensão da realidade escolar. Todas essas ações têm como objetivo promover o desenvolvimento intelectual, social e emocional dos sujeitos e se sustentam em técnicas e teorias da Psicologia. Contudo, não há ainda uma lei, em âmbito nacional, que garanta a inserção do psicólogo nas escolas e que forneça diretrizes para sua atuação. Desde o ano 2000 tramita no senado o Projeto de Lei 3688/2000 (2000), que dispõe sobre a inserção e prestação dos serviços de psicologia e de assistência social nas escolas básicas; tendo sido aprovado em votação neste ano de 2015 e aguarda sua sanção.

Na Lei de Diretrizes e Bases da Educação Nacional ( $n^{\circ}$ 9.394/96, de 20 de dezembro de 1996), encontramos apenas duas menções ao termo psicológico (a). No artigo 30 da Seção II - Da Educação Infantil, esta é definida como uma etapa da educação básica que tem a finalidade de proporcionar o desenvolvimento integral da criança, no qual se encontra o psicológico; e, no artigo 71, inciso IV, do Título VII - Dos Recursos Financeiros, a assistência psicológica, juntamente com a farmacêutica, a odontológica e a médica, não é considerada como despesa de manutenção e desenvolvimento do ensino.

A falta de uma legislação que afirme a importância dos serviços de Psicologia na escola pode ser apontada como uma das causas para o desinteresse dos profissionais em atuar na área ${ }^{3}$. Diferentemente desta situação, em Portugal é possível encontrar referência ao psicólogo escolar na Lei de Bases do Sistema Educativo, no artigo $26^{\circ}$ da Lei ${ }^{\circ}$ $46 / 86$ de 14 de outubro, reafirmada no artigo $29^{\circ}$ da versão revista da mesma lei (Lei $n^{\circ}$ 49/2005 de 30 de agosto). Expressam os referidos artigos: "O apoio no desenvolvimento psicológico dos alunos e à sua orientação escolar e profissional, bem como o apoio psicopedagógico às actividades [sic] educativas e ao sistema de relações da comunidade escolar, são realizados por serviços de psicologia e orientação escolar profissional inseridos em estruturas regionais escolares".

Em atendimento a este artigo da Lei de Bases, há o Decreto-Lei no 190/91, de 17 de maio, que cria os Serviços de Psicologia e Orientação (SPO) ${ }^{4}$. Esses serviços, assim nomeados, caracterizam-se pela organização em equipes uni e multidisciplinares, compostas por psicólogos, técnicos de serviço social e professores - denominados especialistas de apoio educativo. Essas equipes desenvolvem seu trabalho em escolas pertencentes às Direções Regionais de Educação (DREs) - das quais são dependentes e coorde-

3 De acordo com Yamamoto (2012), que toma por base pesquisa realizada em 2010 pela ANPEPP, nesse ano havia 236 mil psicólogos inscritos no Ministério da Educação - MEC, dos quais 53\% dos participantes da pesquisam dizem atuar na área clínica. Revela-se, ainda, que $27,9 \%$ dos psicólogos encontram-se na saúde, $25,1 \%$ na área do trabalho e das organizações, e apenas $9,8 \%$ na área educacional.

4 Para maiores informações, consultar Leitão, Paixão, Silva e Miguel (2001). nados, seguindo o Plano Anual de Atividades (PAAs), elaborado pelo psicólogo. As metas desse plano, após aprovação dos órgãos de gestão, passam a fazer parte das atividades da respectiva unidade escolar. Os profissionais que neles atuam devem prestar orientação educativa a alunos, por meio de acompanhamento individual ou grupal, buscando promover o desenvolvimento pessoal e de relações, seja na educação pré-escolar, ou do $1^{\circ}$ ao $3^{\circ}$ ciclo do ensino básico.

A descrição sobre as atribuições dadas a esses serviços, encontradas no artigo $3^{\circ}$ do referido decreto-lei, nos aproxima do que foi pontuado por Jesus (2004), quando afirma que ainda podemos observar uma descrição centrada nos alunos e, diríamos, na promoção de seu sucesso escolar a partir das aptidões que possuem, além da preocupação em responder, talvez, às demandas do mercado de trabalho por meio da orientação profissional. Porém, ao mesmo tempo, essas atribuições revelam avanços, na medida em que oferecem margem para se propor ações que transponham essa delimitação, sobretudo junto aos professores e, ainda, na ideia de parceria com os profissionais e na menção a atuar "nas relações". Ou seja, em Portugal, além do serviço previsto em lei, há diretrizes que, se não plenamente adequadas a ações voltadas ao coletivo, oferecem lastro para se pensar práticas mais efetivas.

Leitão, Paixão, Silva e Miguel (2001) trazem dados importantes acerca do trabalho do psicólogo nos Serviços de Psicologia e Orientação (SPO). Por meio de questionários aplicados aos psicólogos que trabalhavam nesses serviços, a alunos das escolas, e um questionário de entrevistas dirigido aos professores e órgãos de gestão, buscaram caracterizar esses serviços e verificar como esses sujeitos compreendiam o papel dos psicólogos nas escolas. De modo geral, puderam verificar que tanto os órgãos de gestão, como os professores e alunos consideram importantes as atividades desenvolvidas pelos psicólogos dos serviços e a eficácia destes torna-se ainda mais evidente quando se tem estabelecida uma parceria entre os psicólogos e esses atores escolares.

Evidenciou-se, também, que são necessárias meIhorias quanto às condições de trabalho dos psicólogos e em relação aos materiais que Ihes são disponibilizados (espaços físicos, materiais de trabalho - tais como testes e recursos tecnológicos), além da verba destinada para esses serviços. Os psicólogos relataram ser interessante a ampliação das equipes que trabalham nos serviços, ou seja, que houvesse outros profissionais que contribuíssem para a melhoria dos serviços prestados, no desenvolvimento de um trabalho multidisciplinar. Verificou-se, também, que ainda não há, por parte dos psicólogos inquiridos, um consenso acerca de um modelo definido no que se refere à formação, atualização e supervisão de sua atuação no serviço. 40,4\% dos psicólogos, de um total de 64, informaram que seria importante a troca de experiências com outros profissionais e um plano de supervisão e formação (inicial e contínua), que contribuísse para a delimitação e clarificação das atividades desenvolvidas nos serviços (Leitão \& cols., 2001). 
Os autores terminam por fazer uma proposta de atuação nos serviços que busque a criação de uma rede, em que sejam consideradas as dimensões da saúde e de apoio psicopedagógico. Essa forma de serviço teria como objetivo a "detecção precoce de situações potencialmente desencadeadoras de insucesso escolar" (p. 51), já no início da vida escolar dos alunos, nomeadamente, no jardim de infância e no $1^{\circ}$ ciclo. Esse trabalho seria desenvolvido em conjunto com professores e centros de saúde. Além disso, caberia promover a formação contínua desses professores no que diz respeito a oferecer apoio na compreensão dos processos de aprendizagem e acompanhamento das situações consideradas mais problemáticas, em vista da promoção do sucesso escolar.

Entendemos que as considerações apresentadas por esses autores, sobretudo na proposta que fazem, carregam o viés da individualização e do desenvolvimento de competências, que parece ser norteador dos serviços de Psicologia, conforme já apontamos. A ideia de prevenção, ainda nos moldes deterministas que colocam o meio como influência determinante do desenvolvimento, também fica evidente. Entretanto, por outro lado, seus estudos revelam a preocupação em se avaliar o trabalho realizado pelos psicólogos escolares, indicando fragilidades e propondo mudanças. Esse é um movimento que gostaríamos de ver crescer no Brasil; contudo, acreditamos que sem a institucionalização da função promovida pela legislação é algo que permanece como horizonte.

Ter uma lei que garanta a inserção do psicólogo nas escolas é, de nosso ponto de vista, um avanço para que essa área seja afirmada como tal, e pode contribuir para a construção da identidade desse profissional, já que auxilia na clarificação do que lhe cabe, na medida em que fornece diretrizes para as suas ações. Porém, pensamos que seja necessário ter avanços nessas leis, também, para que embasem ações que atentam àquilo que, como vimos, vem sendo defendido há algum tempo: uma atuação que procure atender às demandas da escola como um todo, de seus sujeitos como sujeitos em relação, considerando as condicionantes produzidas pela transformação da sociedade como um todo e, sobretudo, pelo modo de organização social que se sustenta no modelo capitalista.

Outra consideração a se fazer é que, para além de trabalhar com as políticas públicas, sendo essa reconhecidamente um campo de atuação do psicólogo, no Brasil precisamos, antes, de políticas públicas que garantam espaço de atuação do psicólogo nas escolas.

\section{Considerações Finais}

Reconhecemos que a posição que temos ocupado na escola, decorrente de um lugar não legitimado institucionalmente ou legalmente, constitui-se como grande complicador de nossas ações. Ou seja, é preciso que se avance no movimento de inserção do psicólogo nas redes de ensino e este é um desafio de todos nós. E essa não é uma realidade vivida somente no Brasil; como pudemos ver, em Portugal ainda há um campo aberto nas discussões que se referem à consolidação da Psicologia escolar como área de atuação e de pesquisa.

Sabemos que conquistar este lugar legítimo implica ir além da legislação e políticas; passando, por exemplo, pela reestruturação dos currículos de formação do psicólogo que, além de atuar como tal, atua como formador de professores em cursos de licenciatura, ensinando disciplinas de Psicologia. Essa é uma limitação de nossa discussão, mas que oferece uma abertura para outras pesquisas: que formação é necessária para que o psicólogo desenvolva uma prática crítica, seja como profissional atuando nas escolas ou redes ou na docência em cursos de licenciatura e de Psicologia? Sem dúvida esta é uma questão que, embora venha sendo discutida por muitos dos estudiosos, ainda carece de maior aprofundamento.

Apesar de haver psicólogos atuando nas redes de ensino, ainda há prejuízos no que diz respeito às suas ações, pois o número de profissionais inseridos nesse campo não atende às demandas que emergem desses contextos. Porém, ao mesmo tempo, essas atribuições revelam avanços, na medida em que oferecem margem para se propor ações que transponham essa delimitação, sobretudo junto aos professores e, ainda, na ideia de parceria com os profissionais e na menção a atuar "nas relações". Ou seja, em Portugal, além do serviço previsto em lei, há diretrizes que, se não plenamente adequadas a ações voltadas ao coletivo, oferecem lastro para se pensar práticas mais efetivas.

Precisamos mais do que trabalhar com as políticas públicas, pois mesmo sendo esse reconhecidamente um campo de atuação do psicólogo no Brasil, precisamos, antes, de políticas públicas que garantam espaço de atuação do psicólogo nas escolas. Pensamos que também seja importante ouvir o que tem sido feito pelos profissionais, mesmo que raros, para tomarmos conhecimento das demandas e intervenções realizadas, assim como viabilizar a divulgação dos resultados de pesquisas que possam iluminar a atuação desses profissionais.

\section{Referências}

Almeida, L. S. (1993). Psicologia Escolar e Psicologia da Educação em Portugal: elementos caracterizadores da situação presente. Em R. S. L. Guzzo, L. S. Almeida, \& S. M. Wechsler (Orgs.), Psicologia Escolar: padrões e práticas em países de língua espanhola e portuguesa (pp. 129-146). Campinas, SP: Editora Alínea.

Almeida, L. S. (2003). Psicologia escolar em Portugal. Em S. N. Jesus (Org.), Psicologia em Portugal: balanços e perspectivas (pp. 1343). Coimbra, PT: Quarteto Editora.

Antunes, M. A. M. (2003). Psicologia e educação no Brasil: um olhar histórico-crítico. Em M. E. M. Meira \& M. A. M. Antunes (Orgs.), Psicologia Escolar: teorias críticas. (pp. 139-168). São Paulo, SP: Casa do Psicólogo. 
Carvalho, R. G. G. (2008). A dimensão relacional da intervenção dos serviços de Psicologia nas escolas. Psicologia: Reflexão e Crítica, 21 (1), 119-124. Recuperado: 26 jun. 2012. Disponível: www. scielo.br/prc.

Coimbra, J. L. (1991). O psicólogo face aos outros profissionais da Educação: reflexões sobre a consultadoria psicológica. Cadernos de Consulta Psicológica, 7,21-26.

Conselho Federal de Psicologia (2007). Resolução $n^{\circ}$ 13/2007. Recuperado: 03 dez. 2015. Disponível: http://site.cfp.org.br/wpcontent/uploads/2008/08/Resolucao_CFP_nx_013-2007.pdf

Decreto-Lei 190/91, de 17 de maio de 1991. (1991). Cria nos estabelecimentos de educação e ensino públicos os serviços de psicologia e orientação. Ministério da Educação de Portugal. Recuperado: 04 jul. 2007. Disponível: http://euroguidance.gov.pt/ data/euroguidance/decreto_lei_n_190_91.pdf

Guzzo, R. S. L. \& Mezzalira, A. S. C. (2011). 2008 - Ano da Educação para os psicólogos: encaminhamentos e próximos passos. Em R. S. L. Guzzo \& C. M. Marinho-Araujo (Orgs.), Psicologia escolar: identificando e superando barreiras (pp. 11-31). Campinas, SP: Editora Alínea.

Guzzo, R. S. L., Mezzalira, A. S. C., Moreira, A. P., Tizzei, R. P., \& Silva Neto, W. M. F. (2010). Psicologia e Educação no Brasil: uma visão da historia e possibilidades nessa relação. Psicologia: Teoria e Pesquisa. 26(n. especial), 131-141. Recuperado: 26 jun. 2012. Disponível: http://www.scielo.br/pdf/ptp/v26nspe/a12v26ns.pdf

Jesus, S. N. (2004). Psicologia da Educação. Coimbra, Portugal: Quarteto Editora.

Lei n. 46/86, de 14 de outubro de 1986. (1986). Dispõe sobre a Lei de Bases do Sistema Educativo. Ministério da Educação de Portugal. Recuperado: 04 jul. 2012. Disponível: http://intranet.uminho.pt/ Arquivo/Legislacao/AutonomiaUniversidades/L46-86.pdf

Lei n. 9.394, de 20 de dezembro de 1996. (1996). Dispõe sobre a Lei de Diretrizes e Bases da Educação Nacional. Ministério da Educação. Brasil. Recuperado: 04 jul. 2007. Disponível: http:// www.planalto.gov.br/ccivil_03/leis/L9394.htm

Lei n. 3688, de 31 de outubro de 2000. (2000). Dispõe sobre a prestação de serviços de psicologia e de assistência social nas escolas públicas de educação básica. Recuperado: 04 jul. 2012. Disponível: http://www.camara.gov.br/proposicoesWeb/fichadetra mitacao?idProposicao $=486569$

Lei n. 49/2005, de 30 de agosto de 2005. (2005). Lei de Bases do Sistema Educativo. Recuperado: 04 jul. 2012. Disponível: http://www.fenprof.pt/Download/FENPROF/SM_Doc/Mid_132/ Doc_1172/Anexos/LBSE\%20Lei\%2049\%202005.pdf
Leitão, L. M., Paixão, M. P., Silva, J. T., \& Miguel, J. P. (2001). Ser Psicólogo em Contexto Escolar: os serviços de psicologia e orientação (SPO's) na região centro. Psychologica, 26, 27-53. Recuperado: 27 jun. 2012. Disponível: http://gaius.fpce.uc.pt/ pessoais/jpacheco/pdf/Psychologica26_27_53.pdf

Machado, A., Lourenço, O., Pinheiro, A., \& Silva, C. (2004). As duas faces de Janus da psicologia em Portugal. Análise Psicológica, 2(22), 319-333. Recuperado: 29 jun. 2012. Disponível: http://www. scielo.gpeari.mctes.pt/pdf/aps/v22n2/v22n2a02.pdf

Marinho-Araujo, C. M. (2010). Psicologia Escolar: pesquisa e intervenção. Em aberto, 23(83), 15-35.

Mendes, S. A., Abreu-Lima, I., \& Almeida, L. S. (2013). Psicólogos escolares em Portugal: contributos para a sua caracterização profissional. Psicologia, Educação e Cultura, 27 (1), 190-208. Recuperado: 03 dez. 2015. Disponível: http://www.researchgate. net/publication/280307248_Psiclogos_escolares_em_Portugal_ Contributos_para_a_sua_caracterizao_profissional.

Ministério do Trabalho do Brasil (2008). Catálogo Brasileiro de Ocupações [CBO]. Recuperado: 24 mai. 2012. Disponível:http:// www.pol.org.br/pol/export/sites/default/pol/legislacao/ legislacaoDocumentos/atr_prof_psicologo_cbo.pdf

Petroni, A. P. (2013). Psicologia Escolar e arte: possibilidades e limites da atuação do psicólogo na promoção da ampliação da consciência de gestores. Tese de Doutorado em Psicologia como Profissão e Ciência, Pontifícia Universidade Católica de Campinas, Centro de Ciências da Vida, Programa de Pós-Graduação em Psicologia, Campinas, SP.

Silva Neto, W. M. F. (2015). A atuação do psicólogo escolar em Portugal: da legislação ao cotidiano. Em anais do XII CONPE $37^{a}$ ISPA Conference. São Paulo, SP: Universidade Presbiteriana Mackenzie. Recuperado: 03 dez. 2015. Disponível: https:// abrapee.files.wordpress.com/2015/10/anais-xii-conpe-versc3a3ofinal.pdf.

Souza, M. P. R. (2010). A atuação do psicólogo na rede pública de educação: concepções, práticas e desafios. Tese de LivreDocência, Departamento de Psicologia da Aprendizagem, do Desenvolvimento e da Personalidade, Instituto de Psicologia, Universidade de São Paulo. São Paulo, SP.

Souza, V. L. T. (2008). Psicologia e Compromisso Social: reflexões sobre as representações e a identidade do Psicólogo Escolareducacional. Revista Eletrônica de Psicologia e Políticas Públicas, 1(1), 14-34.

Yamamoto, O. H. 50 anos de profissão: responsabilidade social ou projeto ético-político? Psicologia Ciência e Profissão, 32 (número especial), 6-17. Recuperado: 28 nov. 2012. Disponível: http://www. scielo.br/pdf/pcp/v32nspe/v32speca02.pdf 
Recebido em: 12/01/2015

Reformulado em: 06/12/2015

Aprovado em: 20/01/2016

\section{Sobre as autoras}

Ana Paula Petroni (anappetroni@gmail.com)

Psicóloga; mestre e doutora pelo Programa de Pós-graduação em Psicologia como Profissão e Ciência da Pontifícia Universidade Católica de Campinas.

Vera Lucia Trevisan de Souza (vtrevisan@puc-campinas.edu.br)

Psicóloga; mestre e doutora em Educação (Psicologia da Educação) pela Pontifícia Universidade Católica de São Paulo, docente e coordenadora do Programa de Pós-graduação em Psicologia como Profissão e Ciência da Pontifícia Universidade Católica de Campinas.

Esta pesquisa contou com o apoio financeiro da Coordenação de Aperfeiçoamento de Pessoal de Nível Superior (CAPES) com a bolsa para o doutorado e doutorado sanduíche. 